\title{
PLM Impact Analysis Model - PIA
}

\author{
Simo-Pekka Leino ${ }^{1}$, Juha-Pekka Anttila ${ }^{1}$, Juhamatti Heikkilä ${ }^{2}$, Joonas Aaltonen ${ }^{2}$, \\ Kaj Helin ${ }^{1}$ \\ ${ }^{1}$ VTT Technical Research Centre of Finland, Tampere, Finland \\ \{simo-pekka.leino, juha-pekka.anttila, kaj.helin\}@vtt.fi \\ ${ }^{2}$ Metso Minerals, Finland \\ \{juhamatti.heikkila, joonas.altonen\}@metso.com
}

\begin{abstract}
Our goal was to create a support for better PLM development target identification. A method titled "PIA - PLM Impact Analysis" was created in order to help recognizing the most value-adding potentials. The method is supported by a MS-Excel based tool. The method was built and developed in workshops interactively with researchers and representatives from companies.

So far the PIA method and tool has been tested in two large industrial companies from heavy machinery segments. Results from testing the PIA tool are encouraging. The most remarkable benefits of the tool are achieved by improved communication and discussion between departments and functions, and the systematic way of gathering and analysing data. In the future work usability of the tool will be extended. The gathered data will be analysed and synthesized in order to build better generic future PLM models.
\end{abstract}

Keywords: PLM, impact, analysis, benefit, defect, potential

\section{Introduction}

Companies are facing many challenges in forms of for instance globalization, environmental awareness, shrinking product lifecycles, more complex products, and supply chains. Product Lifecycle Management (PLM) is a strategic approach which is expected to solve many problems and streamline business by integrating efficiently people, processes, product information, and technology, see e.g. [1], [2]. PLM is claimed to be one of the key enablers for the effective management of product development and product creation processes [3]. Anyhow, few organizations exploit the true benefits of PLM because lack of clear understanding of what PLM is, its core features and functions, and its relationship to many software systems [4]. Companies are not sure to what degree the process integration is reasonable [5]. Companies should understand that PLM is not a ready to use solution but rather a framework, which can be used as a reference for developing company specific concepts and implementation roadmaps [3].

Nowadays departments and functions in industrial companies are often working in their own silos. Communication and data/information sharing is often limited between

adfa, p. 1, 2011.

(C) Springer-Verlag Berlin Heidelberg 2011 
departments and functions in industrial companies as well as between networked organizations. One does not always know how the quality of produced product data effects on the other stakeholders of the product lifecycle. On the other hand, there are often areas in PLM landscape which are not covered well or at all.

A jointly funded research project called "Fudge - Future models for digital and global extended enterprises" was launched in 2010 with aim to investigate present PLM state-of-practice in global large companies, and to propose new PLM models for improving the implementations. The overall process of the research is presented in the Fig. 1. In the beginning of the project it was obvious that there was lack of decent methodology for identification the most remarkable problems and development targets within PLM in companies. One task of the project was focused to creating support for systematic development target identification.

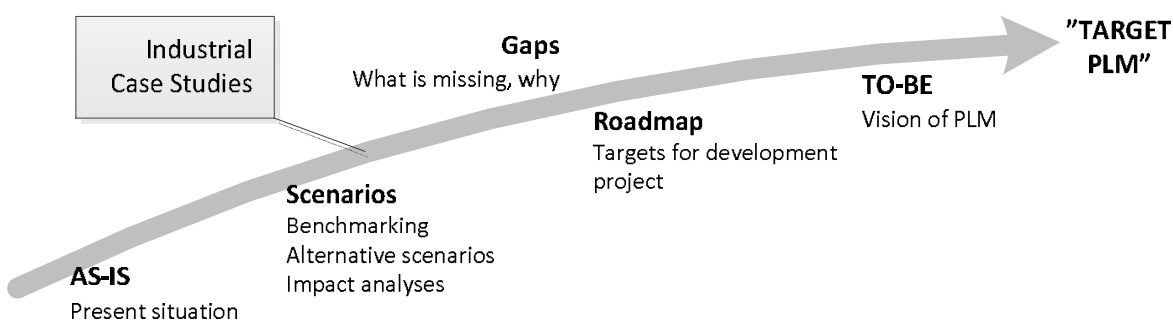

Fig. 1. Overall process of the research

\subsection{Research Question and Objective of the Paper}

Our research question was formulated as follows: How future PLM model and process development and implementation can be supported more systematically and efficiently?

The research question in mind, we set the following goals for the study:

1. Systematic method for identification of a) the most critical problems in present PLM, and b) the most potential new areas of PLM landscape to be implemented

2. New understanding and knowledge about state-of-practice and challenges related to PLM

3. Identification of new research and development targets

\subsection{Structure of the Paper}

In the following section 2, firstly FMEA and Lean approaches are shortly explained as basis material for our study. Then the industrial cases and iterative workshop process is described. In the section 3 results are revealed. The results consist of 1) a created method called "PLM Impact Analysis - PIA", 2) a MS-Excel based tool to support the method, and 3) findings that were gathered using the method and tool. 


\section{$2 \quad$ Method and Material}

Our goal was to create a new method for better PLM development target identification. Our method development process was based on two case studies in two different industrial companies. The developed PIA method is loosely based on FMEA - Failure Mode and Effect Analysis method and the basics of Lean principles.

In the following sections 2.1 and 2.2, the well-known methods and approaches of FMEA and Lean are shortly introduced as basis for our own method development. In the section 2.3, the overall iterative method development process including industrial cases and workshops is explained.

\subsection{FMEA Method}

The developed PIA method is loosely based on well-known method called FMEA Failure Mode and Effect Analysis method, see e.g. IEC 60812 standard [6]. Basic idea of the FMEA method is to analyze potential failure modes within a machine system, and classify severity and likelihood of the failures. FMEA is widely used method of product development in manufacturing industry.

\subsection{Lean Approach in PLM}

Lean is a famous principle of getting rid of any waste within a production system. For instance Morgan and Liker [7] have described how lean principles were implemented in the Toyota Product Development System. Product Lifecycle Management (PLM) is outcome of lean thinking as well [2]. PLM eliminates waste and maximizes efficiency across all aspects of a product's life, not just in its manufacture.

\subsection{Industrial Cases and Workshops}

The PIA method and tool have been created and tested in two companies from heavy machinery industry. One of these two companies is producing mainly configurable serial products, and another is focusing on large delivery project business. Therefore it was possible to gather data from both serial and project business models.

Our research method was based on process of several iterative and interactive workshops with the case companies. The first version of PIA method and tool was built by researchers. After that it has been developed in couple of workshops interactively with researchers and representatives from the company's PDM/PLM experts. Between the workshops researchers made modifications and new updates to the PIA tool. When PIA was ready to use, it was used as a systematic way of gathering and analysing data.

The PIA method and tool include three main phases. When the first version of PIA was ready to use, the first phase was initiated. The first phase continued in the next couple of workshops. Product data related defects and potentials were recognized systemically, as well as their consequences. Company's PDM/PLM experts and re- 
searchers were participating to those first phase workshops. During the first phase company's representatives decided which functions and departments are needed to participate in the second and third phases of the method.

In the second phase all the needed functions were participating to the discussions and work done in the workshops. The involved functions and departments included product design and development, product data support, production, purchase, sales, logistics, commissioning, and after market. Second phase included 3-4 workshops and the groups were larger than earlier in the first phase workshops. It was important that all the functions took part to the workshops, because the probabilities and criticalities of the consequences were analysed by the functions, and the consequences were discussed and recognized in more detailed level.

In the last third phase sources of the most significant problems or potentials were identified by the representatives of the functions. Third phase included 3-4 workshops, and the group was the same as in the second phase workshops. During these workshops, annual costs caused by the most significant problems were estimated. After that, possible actions for reaching a desired situation, when failure causes are removed, were worked out as well. Total development budget estimation was also drafted.

Consequently, the method was based on the workshops and the work done between the workshops. It took more than ten workshops in total in both companies to create, develop, and go through this PIA method. Researchers made modifications and new updates to PIA tool itself, and its content between the workshops.

\section{Results}

The results consist of the created PLM Impact Analysis method and tool, as well as findings about major PLM development targets within the case companies.

\subsection{PLM Impact Analysis (PIA) Method}

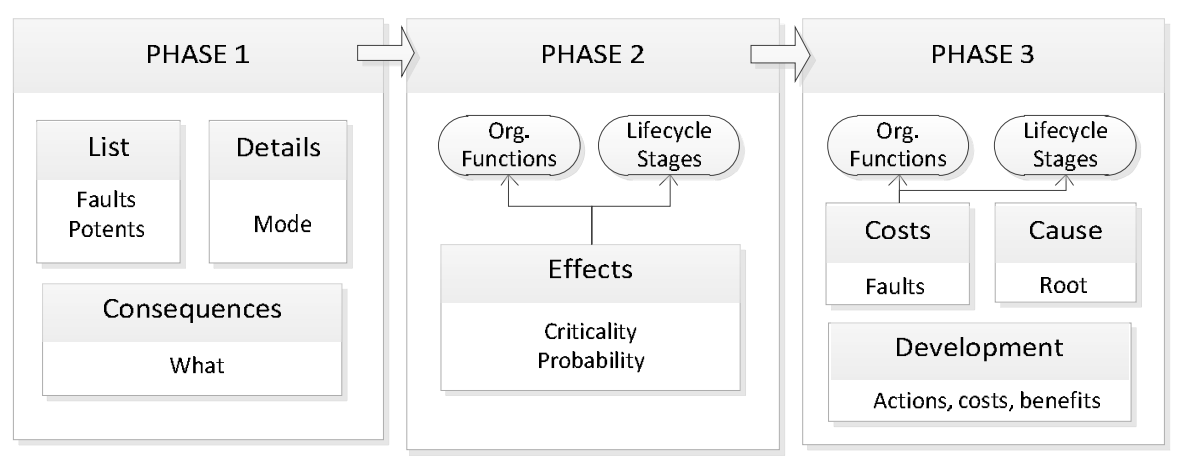

Fig. 2. Three-phased PLM Impact Analysis Method 
A method called "PIA - PLM Impact Analysis" was created in order to help recognizing the most value-adding potentials. The method is supported by a MS-Excel based tool. The method and tool were built and developed in workshops interactively with researchers and representatives from companies. The PIA is intended to support both identification of current problems and failures of product data and processes, and possible potential new areas of PLM landscape implementations.

The method includes three main phases (Fig. 2). In the first phase, product data related defects and potentials are recognized systemically, as well as their consequences. It is important that company's PDM/PLM experts are participating to all of these three main phases, but it is possible to go through the first phase without having all the functions or departments participating. During the first phase it has to be decided which functions and departments are needed to participate in the second and third phases.

In the following second phase, probability and criticality of the consequences are analysed and scored by functions or departments. Also the consequences are discussed and recognized in more detailed level. It is important that all the needed functions or departments are participating actively and openly to the discussions and work done in this phase.

Finally in the last third phase, root causes and sources of the most significant problems or potentials are identified. Representatives of the functions or departments must also estimate the annual costs which are caused by these most significant problems, or similarly annual savings of new PLM implementations. Possible actions for reaching the desired situation are worked out as well. It is also needed to estimate the total costs caused by the development work needed to reach the desired situation. As main outcome of the PIA analysis, PLM development targets can be ranked based on comparison of annual failure costs/potential savings, and development costs.

\subsection{MS Excel Tool Prototype}

The created MS-Excel based tool prototype includes the process and phases that are described in the paragraph 3.1. When the Excel-sheet is populated in workshops during the PIA analysis, 11 diagrams are plotted automatically. The diagrams include several different failure effectivity scores, annual failure costs, and estimated development costs compared to failure costs. Error! Reference source not found.

\subsection{Findings from Industrial Cases}

Key findings about causes and effects of product data failures, PLM process problems and IT-systems are illustrated in Table 1. 
Table 1. Key problem categories, failures, and consequences

\begin{tabular}{|c|c|c|c|}
\hline \multicolumn{3}{|c|}{ Failure Categories } & Consequences \\
\hline $\begin{array}{l}\text { Product Data } \\
\text { Item } \\
\text { Id code: missing, wrong } \\
\text { Duplicates } \\
\text { Classification } \\
\text { Attributes: mass, dimen- } \\
\text { sions, customs code, } \\
\text { serial \#, etc. } \\
\text { Descriptions } \\
\text { Legacy data } \\
\text { Item Structure } \\
\text { Generic structure } \\
\text { Product individual } \\
\text { Configurator: rules, } \\
\text { updating, prices } \\
\text { Documents } \\
\text { Specifications, 3D, } \\
\text { drawings, etc } \\
\text { Status, revision } \\
\text { "White-spots" in speci- } \\
\text { fications }\end{array}$ & $\begin{array}{l}\text { Processes } \\
\text { Item/document work- } \\
\text { flow: } \\
\text { Status, approval } \\
\text { Change management } \\
\text { Change timing, content, } \\
\text { extent } \\
\text { Change bulletins } \\
\text { Un-official, hidden } \\
\text { changes } \\
\text { Feed-back from lifecy- } \\
\text { cle stages } \\
\text { Data ownership } \\
\text { Responsibility } \\
\text { Updates } \\
\text { Access management } \\
\text { Data healing } \\
\text { Not systematic } \\
\text { Knowledge mgt } \\
\text { New technologies } \\
\text { Know-how, know-who } \\
\text { Knowledge sharing } \\
\text { System engineering } \\
\text { Requirements definition } \\
\text { and management } \\
\text { Support for abstract } \\
\text { product definitions } \\
\text { Mechatronic product } \\
\text { structure }\end{array}$ & $\begin{array}{l}\frac{\text { IT-Systems }}{\text { System integrations, }} \\
\text { interfaces } \\
\text { Lack of decent process } \\
\text { and product data } \\
\text { model definitions } \\
\text { Lack of implemented } \\
\text { functionalities }\end{array}$ & $\begin{array}{l}\text { Bad quality of product } \\
\text { data } \\
\text { Data distrust } \\
\text { Un-usable data in IT } \\
\text { Bad traceability } \\
\text { Bad predictability, } \\
\text { management } \\
\text { Fault repeat } \\
\text { Partial optimization } \\
\text { Safety risks, environ- } \\
\text { mental issues } \\
\text { Decreased customer } \\
\text { satisfaction } \\
\text { Out-of-specification, } \\
\text { scrap components/ } \\
\text { products, bad quality } \\
\text { Wrong amount of } \\
\text { components } \\
\text { Re-work } \\
\text { Delays } \\
\text { Production downtime } \\
\text { Logistics problems } \\
\text { Increased cost } \\
\text { Confusions in purchase, } \\
\text { production, logistics, } \\
\text { supply-chain, com- } \\
\text { missioning, sales, } \\
\text { operation, service, etc } \\
\text { Penalties in customs, } \\
\text { warranty } \\
\text { Bad-quality instructions } \\
\text { and manuals } \\
\text { Wrong spare-parts }\end{array}$ \\
\hline
\end{tabular}

In PIA analyses these failures and consequences are then discussed and the root causes of the problems are identified in order to invent corrective action to remove problem causes.

\section{Discussion and Conclusion}

There is lot of business potential which can be reached by implementing PLM landscape more widely and deeply. This requires defining needed processes, practices, information models, meta-models, system architectures and integrations [8]. Our study included all these focus areas. Based on analysis of the case studies' results, process and practices definitions were recognized as major development targets. All of the most significant findings from PIA analysis results and PIA method itself are categorized and summarized in Table 2, and detailed in following chapters. 
Table 2. Summary of the most significant findings from the results analysis

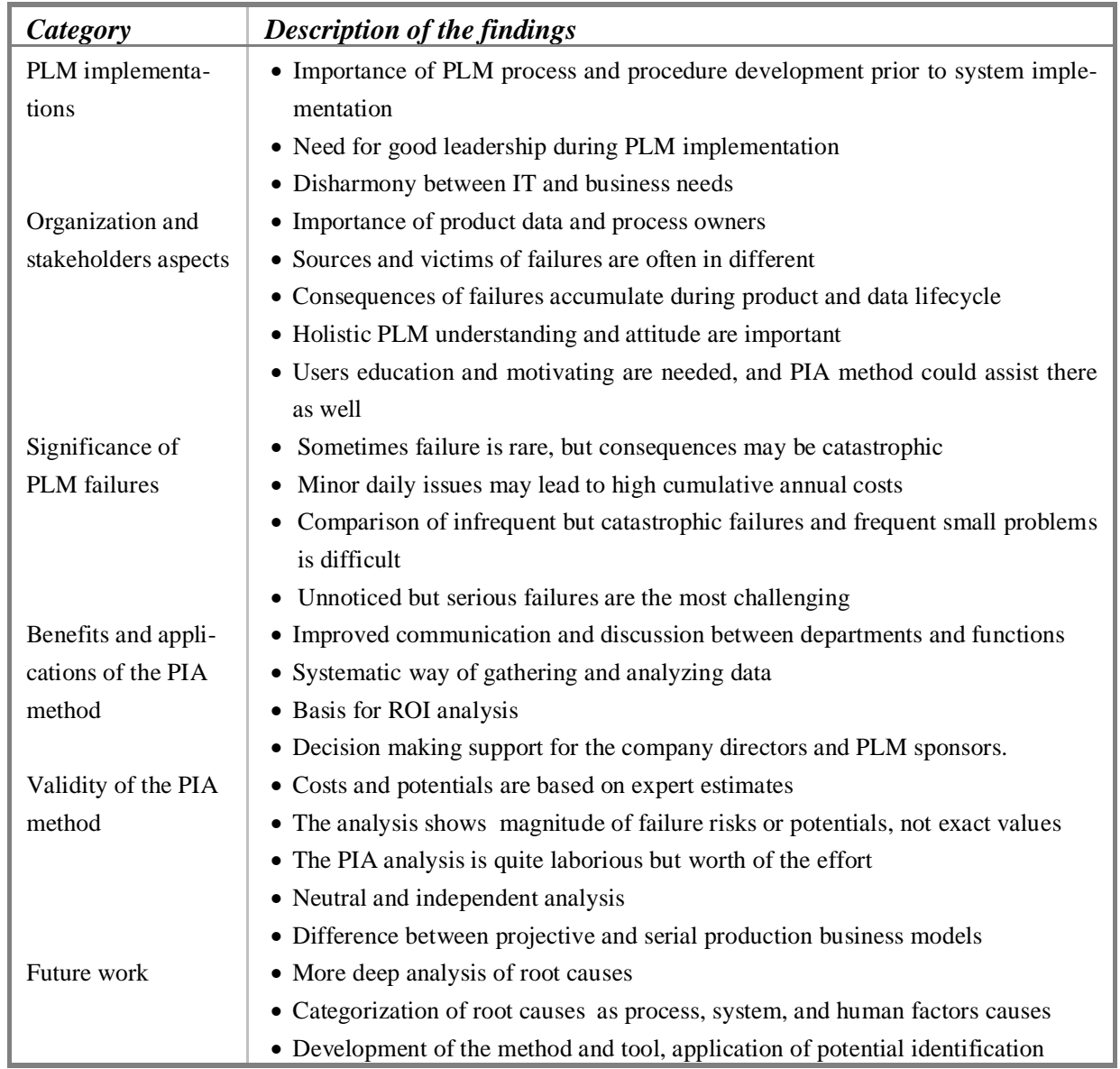

\subsection{PLM implementations}

Usually when PLM problems are discussed the focus is on the IT-systems, like PDM and ERP. Nevertheless, results of our study highlighted the lack of decent PLM processes and procedures. For instance, change management and requirements management seem to be very essential, but not sufficiently supported by PLM. Another remarkable issue besides processes and IT-systems is leadership including organizational change management, people motivation, competence training, etc.

There are also some conflicts between IT-development and business needs. Especially in large global enterprises with many business lines, one common PLM model and implementation is not probably the most optimal approach. However, in reality some compromises are always a necessity. 


\subsection{Organisation and Stakeholders Aspects}

When the corrective actions and PLM development projects are planned, it is naturally essential to recognize who owns the product data and related processes, and what are the actual root causes of the problems. Often the root of the failures is in different company function than the "victim" of the failure. For instance, engineering designers cause many failures of insufficient or incorrect meta-data (attributes, descriptions, etc.) because they are one of the major product data producers of the product lifecycle. On the other hand, consequences of those failures are accumulating during the lifecycle causing great problems and waste e.g. in after-sales. Anyway, guilty hunting is not the purpose, but understanding the big picture. This enables to optimize the wholeness of PLM and planning the right corrective actions. Identification of data and a process owner is essential in order that possible questions and notifications can be addressed to a correct person or group.

In analyses, education and motivating were recognized as major development targets. It is natural that for instance designers will pay more attention to authoring the meta-data correctly if they understand better the consequences during the whole product lifecycle. It is also concluded that the created PIA method and tool may be used as educating and motivating means. Without this kind of systematic approach and discussion with representatives from other functions and stakeholders, consequences are difficult to see from others' viewpoint. In future work creation of PIA based education material will be considered carefully.

\subsection{Significance of PLM Failures}

Sometimes a specific product data or process fault is rare, but when it occurs the consequences may be catastrophic. Naturally, the worst case is death or serious personal injury. For business, consequences that lead to customer dissatisfaction or customer loss are serious as well. Additionally, many less drastic consequences are still remarkably harmful for business. Some "PLM waste", in terms of Lean, occurs daily causing re-work and unnecessary hidden cost, but they are not concerned significant. Anyhow, based on our PIA analysis, those minor daily issues may lead to cumulative annual costs of millions of Euros. This is also one challenge of the PIA model; how to compare those infrequent but catastrophic failures, and frequent small problems. It was also perceived that the most challenging product data failure types are those which are not noticed but which may cause serious consequences. Wrong item code is an example of this type. Sometimes it is also challenging to separate actual failures and normal work. Partly for this reason, failures are corrected case by case but the faulty processes keep repeating the problems.

\subsection{Benefits and Applications of the PIA Method}

So far the error-effectiveness part of the PIA method and tool has been tested in two big industrial companies from heavy machinery and maritime segments. Results from testing the PIA tool are encouraging. The most remarkable benefits of the tool 
are achieved by improved communication and discussion between departments and functions, and the systematic way of gathering and analyzing data. The gathered data is analyzed and synthesized in order to build better generic future PLM models. In the future work usability of the tool, and the new PLM potential part of the tool will be developed and tested.

One of the main principles of Lean thinking is the elimination of waste. In this PIA model study, the elimination of waste can be seen as eliminating or reducing negative impacts of product information failures. Continuous improvement, including the idea of small steps every day, is a part of Lean thinking as well as the idea of cost reduction. PIA model includes also the idea of continuous improvement and process development. One target of the development work done after the PIA analysis is cost reduction by reducing negative impacts of product information failures. With the PIA tool estimated annual data failure cost can be compared to development and failure removal cost (Fig. 3). This serves as fine basis for ROI analysis and decision making support for the company directors and PLM sponsors.

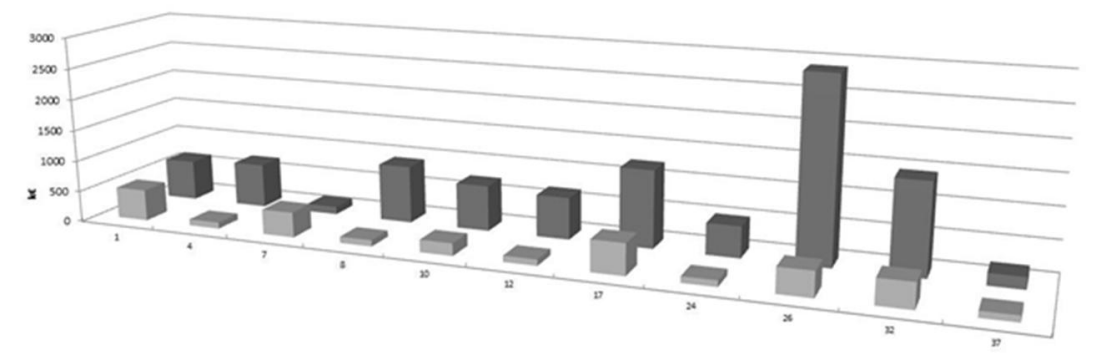

Fig. 3. Estimated development costs compared to yearly failure costs $(\mathrm{X}$ axis $=\mathrm{k} €, \mathrm{Y}$-axis $=$ Row number, problem in product information $)$

\subsection{Validity of the PIA method}

PIA method's weakness is that both failure costs/potential savings and development costs are based on expert estimates. Companies do not typically get automatic reports of product data failures or their costs from their IT systems; therefore costs must be either estimated or calculated manually. This may affect how company management and PLM sponsors respect the analyses results, but quantified results and well-reasoned analysis conclusions are anyways better basis for investments than guesswork.

PIA analysis brings forward magnitude of failure risks or potentials. Normally all risks are not realized, because they are recognized by organization before that. Nevertheless, this causes costs, re-work and confusion, and all potential of PLM is not exploited.

The PIA analysis appeared to be more laborious task than expected. Nevertheless, the case companies found it useful and worth of the effort. The case companies' representatives also reasoned that researchers' role as neutral and independent externals enabled open-minded discussion between functions and departments. 
Result of the PIA analysis in our two cases show also interesting difference between PLM related issues between project business and serial production business model. In large project deliveries project phases and process capabilities are emphasized. Product system requirements and specifications are living during the delivery project and even the customer changes during the project. Projects are often one-off deliveries with different requirements, but still it needs to be supported by common processes and information management without ruining the agility. Product information content, as well as peoples' knowledge seems to be highlighted.

\subsection{Industry cases follow-up and Future Research}

In the industry cases, root causes should be analysed more deeply, and after that annual failure cost should be allocated on them. The root causes should be categorized as process, system, and human factors causes as basis for planning detailed PLM development projects. It is important to analyse which development actions really have significant impact compared to investment.

Schuh et al [9] have introduced a process oriented PLM implementation support framework, which is based on expected benefits. This approach could be combined with PIA potential analysis in order to quantify the holistic PLM benefits. A holistic PLM reference framework model approach created by Marchetta et al [10] could support seeking potential new PLM implementation areas. The PIA method development could also benefit from the PLM effect analysis framework of Cantamessa et al [11] where the effects are categorized at three levels (individual, organizational, and strategic).

\section{Conclusion}

A method called "PIA - PLM Impact Analysis" was created for supporting better PLM development target identification. The method was tested in two industrial cases successfully. Both cases were focused on identification of problems in present PLM implementations, though PIA method could be applied to analysis of potential PLM areas as well. This will be one of the main future research targets of the authors.

The most remarkable benefits of the method are achieved by improved communication and discussion between departments and functions, and the systematic way of gathering and analyzing data.

The conclusions about case analyses results can be crystalized so that processes must be well defined and implemented and communicated to people before all benefits of PLM systems can be gained. Processes need also good execution methods and procedures supported by useful tools. PLM system implementations require also sufficient and rich product data model which support those methods and tools. As examples, processes that need research and development in the future are system engineering, virtual engineering and feedback from product lifecycle stages and stakeholders. This conclusion is supported also for instance by Abramovici [3]. 


\section{Acknowledgements}

All sponsors and colleagues of Fudge (Future models for digital and global extended enterprises" )from the participating companies, Tekes, Tampere University of Technology and VTT, that supported this study, are greatly acknowledged.

\section{References}

1. Stark, J., "Product Lifecycle Management - 21st Century Paradigm for Product Realisation". Springer-Verlag, London (2006)

2. Grieves, M. Product Lifecycle Management - Driving the Next Generation of Lean Thinking. McGraw-Hill (2006)

3. Abramovici, M. Future Trends in Product Lifecycle Management (PLM). The Future of Product Development, Part 12, 665-674 (2007)

4. Ameri, F., Dutta, D. Product Lifecycle Management: Closing the Knowledge Loops. Computer-Aided Design \& Applications, Vol. 2, No. 5 , pp 577-590 (2005)

5. Abramovici, M., Schindler, T. Benefits of PLM in the Automotive Industry. Results of a Benchmark Study. International Conference on Product Lifecycle Management (2010)

6. IEC 60812 Analysis techniques for system reliability - Procedure for failure mode and effects analysis (FMEA)

7. Morgan, J.M., Liker, J.K. The Toyota Product Development System - Integrating People, Process, and Technology. Productivity Press, New York (2006)

8. Srinivasan, V. An integration framework for product lifecycle management. ComputerAided Design 43, 464-478 (2011)

9. Schuh, G., Rozenfeld, H., Assmus, D., Zancul, E. Process Oriented Framework to Support PLM Implementations. Computers in Industry, 59, pp 210-218 (2008)

10. Marchetta, M.G., Mayer, F., Forradellas, R.Q. A Reference Framework Following a Proactive Approach for Product Lifecycle Management. Computers in Industry, 62, pp 672-683 (2011)

11. Cantamessa, M., Montagna, F., Neirotti, P. An Empirical Analysis of the PLM Implementation Effects in the Aerospace Industry. Computers in Industry, 63, pp 243-251 (2012) 